\title{
Biclonal myeloma in renal failure
}

\author{
MILENA K. NIKOLOVA-VLAHOVA', MIROSLAVA KAMBUROVA², JULIETA HRISTOVA ${ }^{2}$, \\ DIMITRIOS VASILEIOU ${ }^{2}$, BORIS BOGOV ${ }^{2}$, RUMIANA KRASTEVA ${ }^{2}$ EVGENI HADJIEV ${ }^{2}$, \\ GERGANA TSVETKOVA ${ }^{2}$, CVETELINA VASILEVA ${ }^{2}$, NIKOLAI HOUBANOV ${ }^{2}$
}

${ }^{1}$ University Hospital St. Ivan Rilski, Sofia, Bulgaria

${ }^{2}$ University Hospital Alexandrovska, Sofia, Bulgaria

\begin{abstract}
Multiple myeloma is a clonal proliferation of the plasma cell line that accounts for approximately 10\% of all hematological malignancies. It is characterized by abnormal growth of plasma cells producing monoclonal immunoglobulin or light chain (paraprotein), with subsequent development of osteolytic bone lesions, anemia, hypercalcemia, and renal failure. In 3-6\% of myeloma patients, more than one monoclonal protein (usually two) is discovered, with different heavy or light chain or both. These additional monoclonal proteins may be identified at the time of diagnosis or appear later during an observation or therapy. The authors describe two patients with biclonal myeloma, one diagnosed during evaluation for newly discovered renal failure, and one identified in the course of treatment of monoclonal gammopathy. The discussion of the diagnosis, natural history, and prognosis in patients with biclonal myeloma are also reported.
\end{abstract}

Key words: myeloma, biclonal, renal failure, diagnosis, natural history, management.

(Centr Eur J Immunol 2020; 45 (1): 122-124)

\section{Introduction}

Multiple myeloma (MM) is a clonal neoplastic disease of the plasma cell line [1]. It accounts for about $10 \%$ of all hematological malignancies. Myeloma is characterized by abnormal growth of plasma cells producing monoclonal immunoglobulin or light chain (paraprotein) with subsequent development of osteolytic bone lesions, anemia, hypercalcemia, and renal failure [1,2].

The diagnosis of myeloma is based on the IMWG criteria such as clonal bone marrow plasma cells $>10 \%$, or biopsy-proven bony or extramedullary plasmacytoma, and one or more of the following CRAB features (hypercalcemia, renal failure, anemia, bone lesions) and myelomadefining events [3]:

End-organ damage that can be attributed to the underlying plasma cell proliferation: hypercalcemia (above upper limits of the normal or $>2.75 \mathrm{mmol} / \mathrm{l}$ ), renal failure (serum creatinine $>177 \mu \mathrm{mol} / \mathrm{l}$ ), anemia (hemoglobin levels at least $20 \mathrm{~g} / \mathrm{l}$ below the lower limits of the normal or $<100 \mathrm{~g} / \mathrm{l}$ ), one or more osteolytic bone lesions (detected with X-ray, computed tomography (CT), or PET/CT). If plasma cells in the bone marrow aspirate are $<10 \%$, then more than one osteolytic lesion should be detected.

One or more of the following biomarkers of malignancy (myeloma-defining events): $>60 \%$ of clonal plasma cells on bone marrow examination, free light chain ratio $>100$ (if the absolute level of the involved light chain is at least $100 \mathrm{mg} / \mathrm{l}),>1$ focal lesions sized $>5 \mathrm{~mm}$ on magnetic resonance imaging (MRI).

In 3-6\% of myeloma patients, more than one monoclonal protein (usually two) can be detected, with different heavy or light chain or both [4]. These additional monoclonal proteins may be identified at the time of diagnosis or appear later during an observation or therapy. Several studies have shown that when the second clone (second paraprotein) appears in the course of treatment, the prognosis and survival are better compared to these in monoclonal gammopathies with single clone; however, others find no such difference [4].

\section{Case report}

\section{Clinical case 1}

A 69-year-old male patient with long-standing history of psoriasis was admitted to the Clinic of Nephrology in May 1996 for diagnostic evaluation of newly found renal failure (serum creatinine, $249 \mu \mathrm{mol} / \mathrm{l}$ ). The clinical laboratory investigations at the admission revealed mild renal failure (serum creatinine, $252 \mu \mathrm{mol} / \mathrm{l}$ ), low hemoglobin level $\left(10^{6} \mathrm{~g} / \mathrm{l}\right)$, total protein level $84 \mathrm{~g} / \mathrm{l}$, albumin level $36 \mathrm{~g} / 1$, mild hypercalcemia (calcium, $2.71 \mathrm{mmol} /$ ), serum IgG $26 \mathrm{~g} / 1$, IgA $0.5 \mathrm{~g} / \mathrm{l}$, IgM $0.4 \mathrm{~g} / \mathrm{l}$, and proteinuria $2.5 \mathrm{~g} / \mathrm{l}$. The serum immunoelectrophoresis revealed monoclonal paraprotein $\operatorname{IgG} \kappa$. Bone marrow aspirate demonstrated

Correspondence: Milena K. Nikolova-Vlahova MD, PhD, University Hospital St. Ivan Rilski, 15 Acad. I. Evst. Geshov Blvd., 1431 Sofia, Bulgaria, e-mail: milena_i_dani@abv.bg

Submitted: 16.04.2018; Accepted: 21.08.2018 
$25 \%$ plasmocytic infiltration. X-ray studies showed single osteolytic lesion in the right femur and the patient was referred to hematology clinic for further treatment. After a treatment with polychemotherapy (6 courses of cyclophosphamide + vincristin + prednisone), serum creatinine dropped to $150 \mu \mathrm{mol} / \mathrm{l}$ and calcium levels decreased to normal limits; no paraprotein was detectable in the urine. Approximately 18 months later, serum immunoelectrophoresis revealed the presence of second monoclonal protein - IgA $\kappa$. Six additional courses of polychemotherapy with cyclophosphamide and prednisone were administered. The patient remained in stable state and died 5 years later of myocardial infarction.

\section{Clinical case 2}

A 76-years-old female patient was admitted to the Clinic of Nephrology in March 2018 for diagnostic evaluation of renal failure (serum creatinine, $198 \mu \mathrm{mol} / \mathrm{l}$ ), anemia (hemoglobin, $102 \mathrm{~g} / \mathrm{l}$ ), and thrombocytopenia (75 G/l).

The clinical laboratory investigations revealed anemia (hemoglobin, $98 \mathrm{~g} / \mathrm{l}$ ) with low platelet count (95 G/l), serum creatinine $179 \mu \mathrm{mol} / \mathrm{l}$, calcium $2.45 \mathrm{mmol} / \mathrm{l}$, total protein $97 \mathrm{~g} / \mathrm{l}$, albumin $44 \mathrm{~g} / \mathrm{l}, \operatorname{IgG} 29.3 \mathrm{~g} / \mathrm{l}$, IgA $0.9 \mathrm{~g} / \mathrm{l}$, $\operatorname{IgM} 0.9 \mathrm{~g} / \mathrm{l}$, and proteinuria $6.4 \mathrm{~g} / 24 \mathrm{~h}$. Serum and urine immunofixation (Fig. 1) revealed biclonal gammopathy $\operatorname{IgG} \kappa+\operatorname{IgG} \lambda$ and the patient was referred to the clinic of hematology for further treatment of biclonal myeloma.

\section{Discussion}

Biclonal myeloma and biclonal gammopathy of unknown significance (BGUS) represent rare clinical entities. Their clinical course, therapeutic response, and survival rates do not differ from that of monoclonal gammopathies [7-10]. The disease is usually diagnosed during diagnostic evaluation for renal failure, anemia, hypercalcemia, or pathological fracture. The diagnostic evaluation may demonstrate both clones at the time of diagnosis, or the second clone may appear in the course of treatment or during follow-up. Usually, biclonal myeloma is associated with two different light chains rather than with two heavy chain subtypes, and the cases expressing both $\kappa$ and $\lambda$ light chains are extremely rate [9]. In patient 1 , we observed an appearance of $\operatorname{IgA} \kappa$ at the background of long-standing IgG $\kappa$ myeloma, and in patient 2 , coexistence of both $\kappa$ and $\lambda$ monoclonal light chains $-\operatorname{IgG} \kappa+\operatorname{IgG} \lambda$. Banerjee et al. [9] reported biclonal myeloma $\operatorname{IgA} \lambda+\operatorname{IgG} \kappa$ as an extremely rare type of gammopathy. Moreover, co-expression of $\kappa$ and $\lambda$ light chain by the same neoplastic plasma cells is rare but reported phenomenon [11].

As to the prognosis, several studies have demonstrated better prognosis when the second clone appeared during therapy [7, 8]. Still, other authors [4] do not find such differences. Little is known about the progression of BGUS

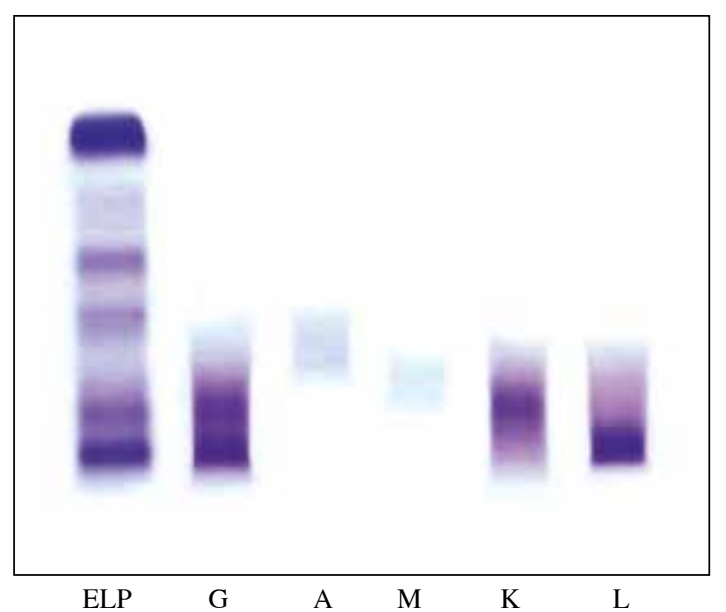

Fig. 1. Serum immunofixation of patient 2 revealing biclonal gammopathy $\operatorname{IgG} \kappa+\operatorname{IgG} \lambda$

and biclonal smouldering myeloma. The progression of monoclonal GUS to myeloma is known to be approximately $1 \%$ per year, and about $10 \%$ of smouldering monoclonal myelomas progress to overt myeloma per year during the first 5 years after diagnosis. The rates of progression of BGUS and biclonal smouldering myeloma to biclonal myeloma are unclear, but the therapeutic response in biclonal myeloma is similar to that of monoclonal. Several studies have shown that the second clone has "protective" role in biclonal myeloma, i.e. the existence or the appearance of a second clone is associated with better therapeutic response, remission rates, and slower progression compared to the monoclonal disease [7, 8]; however, Millikin et al. [4] failed to demonstrate such difference. They revealed that the rate of BGUS progression and biclonal smouldering myeloma do not differ from those in MGUS and smouldering myeloma, and suggested that the two clones are probably a random and independent event and may not be influenced by each other's presence, i.e. both clones have their own evolution [4]. The authors assumed that better outcomes in biclonal gammopathies are probably a result of better immune environment that facilitates the development of a second clone. In general, the main determinant of the therapeutic response and the evolution of the disease is thought to be the dominant clone that usually increases in time, while the other clone remains unchanged in quantity. Nevertheless, the dominant clone may not be the more malignant one [4] and dynamic follow-up is needed.

The follow-up and treatment of biclonal myeloma does not differ from that of monoclonal disease, but dynamic follow-up of both paraproteins is required [7].

In our patients, the main reason for diagnostic evaluation was the presence of renal failure and anemia, with low platelet count in patient 2 . Renal failure in myeloma 
patients can be caused by several factors, including hypercalcemia with hypercalciuria, paraprotein deposition, or precipitation within renal tubuli and other structures, hyperuricemia and hyperuricosuria $[5,6]$. Other factors, contributing to the development of renal failure (especially acute renal injury) in myeloma patients, include dehydration, use of nephrotoxic substances (especially non-steroid anti-inflammatory drugs, NSAIDs, for bone pain), and X-ray contrast agents $[1,2,5,6]$.

In patient 1 , the second clone developed during the treatment and follow-up, and in the second, both clones were present at the time of diagnosis. Both patients showed no differences in the clinical and laboratory investigations and received standard of care. Patient 1 had hypercalcemia and in patient 2, calcium levels were normal, which is not typical for renal failure where calcium is usually low. Both patients had anemia and high total protein levels.

An interesting fact is the association between psoriasis and myeloma in patient 1 . The development of hematological malignancies has been described in psoriatic patients, especially with arthritis [12]. The proposed mechanism for the development of both psoriasis and myeloma is dysregulation of interleukin 6 expression [13].

\section{Conclusions}

Biclonal myeloma represents up to $6 \%$ of all myeloma cases. In general, its course is determined by the dominant component and its natural history, and the therapeutic response do not differ significantly from that of monoclonal types. Myeloma should be suspected in every patient with renal failure of unknown origin in combination with anemia and high/normal or increased serum total protein and calcium levels.

\section{The authors declare no conflict of interest.}

\section{References}

1. Rajkumar SV, Kumar S (2016): Multiple myeloma: diagnosis and treatment. Mayo Clin Proc 91: 101-119.

2. Rajkumar SV (2014): Multiple myeloma: 2014 Update on diagnosis, risk-stratification, and management. Am J Hematol 89: 998-1009.

3. International Myeloma Working Group (IMWG) criteria for the diagnosis of multiple myeloma. http://imwg.myeloma.org/ international-myeloma-working-group-imwg-criteria-for-thediagnosis-of-multiple-myeloma/

4. Mullikin TC, Rajkumar SV, Dispenzeri A, et al. (2016): Clinical characteristics and outcomes in Biclonal Gammopathies. Am J Hematol 91: 473-475.

5. Goldschmidt H, Lannert H, Bommer J, Ho AD (2000): Multiple myeloma and renal failure. Nephrol Dial Transplant 15: 301-304.
6. Dimopoulos MA, Kastritis E, Rosinol L, et al. (2008): Pathogenesis and treatment of renal failure in multiple myeloma. Leukemia 22: 1485-1493.

7. Goranov S (1994): Clinical aspects of biclonal myelomas. Folia Med (Plovdiv) 36: 31-36.

8. Wadhera RK, Kyle RA, Larson DR, et al. (2011): Incidence, clinical course, and prognosis of secondary monoclonal gammopathy of undetermined significance in patients with multiple myeloma. Blood 118: 2985-2987.

9. Banerjee A, Pimpalgaonkar K, Christy AL (2016): A rare case of multiple myeloma with biclonal gammapathy. J Clin Diagn Res 10: BD03-BD04.

10. Jurczyszyn A, Gozzetti A, Gdula-Argasińska J, et al. (2017): Similar survival outcomes in patients with biclonal versus monoclonal myeloma: a multi-institutional matched casecontrol study. Ann Hematol 96: 1693-1698.

11. Jiwani S, Bornhost J, Alapat D. (2015): Biphenotypic plasma cell myeloma: two cases of plasma cell neoplasm with a coexpression of kappa and lambda light chains. Int J Clin Exp Pathol 8: 8536-8844.

12. Rohekar S, Tom BDM, Hassa A, et al. (2008): Prevalence of malignancy in psoriasis. Arthritis Rheum 58: 82-87.

13. Simpson RJ, Hammacher A, Smith DK, et al. (1997): Interleukin-6: structure-function relationships. Protein Sci 6: 929-955. 